\title{
ЮРИУИЧЕСКИЙ ПРАКТИКУМ
}

В. В. Яровенко

\section{КРИМИНАЛИСТИЧЕСКАЯ ХАРАКТЕРИСТИКА ПРЕДМЕТОВ, ИСПОЛЬЗУЕМЫХ В КАЧЕСТВЕ ОРУЖИЯ СОВЕРШЕНИЯ ПРЕСТУПЛЕНИЯ}

Аннотация: В статье рассматриваются различные предметы, макеты, модели, не являющиеся оружием, но используемые при совершении преступления в качестве оружия. Обращается внимание на общественную опасность различных предметов, конструктивно сходных с оружием.Обосновывается позиция об ограничении выпуска таких предметов, так как в отдельных криминальных ситуачиях ошибочно воспринимаются в качестве оружия. Кроме того, они могут быть легко переделаны под оружие.

Ключевые слова: юриспруденция, огнестрельное оружие, холодное оружие, орудия, предметы, макеты, модели, ответственность, экспертиза, исследование.

уголовном кодексе Российской Федерации предусмотрено совершение отдельных преступлений с применением оружия или предметов, используемых в качестве оружия (ч.2 ст. 162 УК РФ, п. «Г» ч. 2 ст. 206 УК РФ, п. «Г» ч. 2 ст. 211 УК РФ, п. «а» ч. 1 ст. 213 УК РФ). Применение оружия закреплено в качестве квалифицирующего признака в 18 статьях Особенной части УК РФ, применение предметов, используемых в качестве оружия, в 8 статьях Особенной части УК РФ. Об использовании при совершении преступлений специально изготовленных технических средств, речь идет в п. «К» ч. 1 ст. 63 УК РФ, а в п. «б» ч.3 ст. 286 УК РФ законодатель называет специальные средства, но не указывает какие. При расследовании указанных преступлений обстоятельством, подлежащим доказыванию, является установление принадлежности предмета к оружию либо предмета, не являющегося таковым, но используемого субъектом в качестве оружия.

Если предмет является оружием, в частности, огнестрельным, холодным, газовым, метательным, то в этих случаях решается вопрос о привлечении лица, применившего его, к уголовной ответственности дополнительно по ст. ст. 222-224 УК РФ. В отдельных криминальных ситуациях, применение оружия может быть общеопасным, например, при выстреле дробью, картечью из обреза в конкретного человека потерпевшими оказываются и близко находившиеся люди из-за разброса поражающих элементов. В пункте «е» ст. 105 УК РФ в качестве квалифицирующего признака предусмотрено совершение убийства общеопасным способом.
В некоторых случаях к рассматриваемым ситуациям можно отнести совершение убийства с применением не только оружий или предметов, используемых в качестве оружия, но и специально изготовленные технические средства, если их использование было общеопасным.

В статье 1 Ф3 «Об оружии» даётся определения оружия вообще и некоторых его отдельных видов, ранее содержащиеся только в специальной литературе. Согласно этой статье оружие - устройства и предметы, конструктивно предназначенные для поражения живой или иной цели, подачи сигналов. При этом и холодное, и метательное оружие вводится как самостоятельные виды. Все виды оружия (огнестрельное, холодное, метательное, пневматическое, газовое, огнестрельное оружие ограниченного поражения), во-первых, предназначены для поражения живой или иной цели; во-вторых, имеют соответствующую конструкциюю для поражения. Закон не относит к оружию различные изделия хозяйственнобытового и производственного назначения, спортивные снаряды, конструктивно сходные с оружием ${ }^{1}$.

Законодателем используется термин «предметы», которыми в следственной практике охватываются предметы: а) конструктивное сходные с оружием; б) не имеющие никакого конструктивного сходства с оружием, но применяемые при совершении преступления в качестве оружия. Так, хозяйственные и туристические ножи не предназначены для поражения, но они могут иметь сходную конструкцию с охотничьим ножом,

${ }^{1}$ См. Федеральный закон «Об оружии». http://www.zakonrf/ zoboruzhii/1/. Запрос 16.12.2011. 
кроме прочности и толщины клинка. Самым распространенным оружием при совершении отдельных видов преступлений является холодное оружие либо предметы по внешним признакам схожие с ним.

Определение предметов, используемых в качестве оружия, содержится в ст. 6 Ф3 “Об оружии” - специально приспособленные для использования в качестве оружия предметы ударно-дробящего и метательного действия: кистени, кастеты, сюрикены, бумеранги, которые криминалистами традиционно относились к холодному либо метательному оружию. В данном случае важно отметить, что речь идёт о предметах, специально приспособленных для использования в качестве оружия. Если предмет специально приспособлен, то это свидетельствует об умышленном характере действий лица.

В следственной практике встречаются следующие типичные криминальные ситуации, когда предметы используются в качестве оружия: а) специально приспособленные; б) заранее приготовленные или взятые хозяйственно-бытовые предметы; в) случайно оказавшиеся под рукой на месте происшествия и используемые в качестве оружия, например, кухонный нож и др. Предметом, используемым в качестве орудия преступления, судебная практика признает и бутылку².

В науке уголовного права под предметами, используемыми в качестве оружия, понимают предметы, которыми потерпевшему могли быть причинены телесные повреждения, опасные для жизни или здоровья (перочинный нож, кухонный нож, бритва, ломик, дубинка, топор, ракетница и т.д.), а также предметы, предназначенные для временного поражения цели (например, механические распылители, аэрозольные и другие устройства, снаряженные слезоточивыми и раздражающими веществами) $)^{3}$.

Полагаем, что уяснение понятия «предмет, используемый в качестве оружия» связано с анализом тех его признаков, которые нашли отражение в тексте самого уголовного закона либо вытекают из его содержания. Таких признаков Р.Д. Шарапов называет три. Во-первых, это то, что соответствующие орудия являются предметами. Во-вторых, данные предметы сами оружием не являются. В-третьих, применение данных предметов связано с их использованием в качестве оружия ${ }^{4}$.

На наш взгляд, этим трем признакам в полной мере отвечают различные макеты (модели) огнестрельного

\footnotetext{
${ }^{2}$ См.: Обзор законодательства и судебной практики Верховного Суда Российской Федерации за третий квартал 1998 г.

${ }^{3}$ См.: Шарапов Р.Д. Преступное насилие. - М.: Изд-во Юрлитинформ, 2009. - С. 388.

${ }^{4}$ См.: Там же. - C. 388.
}

оружия, используемые в качестве предметов совершения преступления. Промышленные предприятия не ограничиваются выпуском только моделей стандартного огнестрельного оружия (макет автомата АК74, АКМ, АКМС, АКС 74, АКС74У, пистолет-пулемет Кипарис, пистолет-пулемет М-11, пистолет-пулемет ППШ), они наладили производство моделей обрезов, по внешнему виду изготовленных из охотничьего оружия.

Боле того, в обход закона вводятся понятия, которые не соответствуют обще принятым критериям, определениям, например, на базе корпуса автомата АКМ конструкторы создали гибрид пистолета «Юнкер 1», а затем пневматическую винтовку «ЮНКЕР $3 »$. По своим конструктивным признакам винтовка отличается от автомата, прежде всего, это длинноствольное оружие, а автомат короткоствольное. Внешний осмотр винтовки свидетельствует о полном сходстве с автоматом: выстрелы через ствол, штатный магазин АК74, наличие штатного ремня, звук затвора при передергивании очень натурален, даже вес соответствует боевому - 3,5 кг. В руководстве по эксплуатации указано, что открытое ношение и имитация применения винтовки как боевого оружия может ввести в заблуждение работников правоохранительных органов и граждан и спровоцировать применение против вас огнестрельного оружия или иных средств самозащиты. Этим самым производитель предупреждает, что нельзя носит винтовку открыто, делайте это скрыто.

Аналогичная ситуация существует и с обрезом «Хорхе», который конструкторы назвали пистолетом. Обрез это криминальное и запрещенное оружие, а пистолет в определенных ситуациях разрешен, поэтому, назвав обрез пистолетом, конструкторы формально не нарушили закон. Ранее конструкторами было создано бесствольное оружие, которые на протяжении длительного времени из-за отсутствия ствола не соответствовало понятию оружие. В настоящее время его популярность среди населения очень велика, законодатель вынужденный считаться с этим, устранил существовавший пробел и ввел определение - огнестрельное оружие ограниченного поражения.

В полнее правомерно поставить вопрос, а для чего изготавливаются и продаются модели, которые могут представлять общественную опасность? В отдельных криминальных ситуациях у потерпевших нет возможности достоверно знать, что на него совершено нападение с макетом пистолета, автомата, обреза или непригодным к стрельбе оружием. Более того, в ряде случаев преступники заряжают оружие и производят выстрелы, зная, что энергии недостаточно для поражения цели. Тем не менее, эти действия производят на потерпевших 
отрицательное воздействие: отказ от активного оказания сопротивления.

На наш взгляд, следует запретить создавать модели газового пневматического, травматического оружия на основе боевого или служебного оружия, которое не только может быть ошибочно воспринято как боевое, но и значительно облегчает его переделку путем замены ствола как на самодельный нарезной, так и не нарезной, но обладающий достаточной кинетической энергией для поражения человека («ИЖ-75» под патрон 5,45 мм, «6П427,6» под патрон 9 мм). Кроме того, целесообразно при создании опытных моделей получать соответствующую консультацию у специалистов- юристов.

Под огнестрельным оружием в науке криминалистике понимаются предметы, специально предназначенные для нападения или активной защиты и поражения цели снарядом, выбрасываемым из ствола силой давления газов порохового заряда или его заменителя, обладающие достаточным поражающим действием для нанесения телесных повреждений и по своему устройству и прочности конструкции позволяющие произвести из них более одного выстрела 5 .

К числу предметов, используемых в качестве оружия, но не являющихся таковым, можно отнести различные виды ручного огнестрельного атипичного оружия, которое не соответствует необходимым конструктивным характеристикам: не достаточно кинетической энергии снаряда; не пригодность к стрельбе и др. Так, в ходе судебно-баллистической экспертизы, эксперт может установить, что кинетическая энергия снаряда не превышает минимальных критериев поражаемости, а поэтому нет оснований для признания пистолета, револьвера, стреляющего устройства огнестрельным оружием. Либо установить, что огнестрельное оружие находится в неисправном состоянии и производство выстрелов из него невозможно. Например, на судебно-баллистическую экспертизу был предоставлен пистолет-пулемёт. В ходе исследования эксперт установил, что в своей совокупности пистолет-пулемет является заготовкой нарезного огнестрельного оружия. Выстрелы из данного оружия в представленном виде не происходят ${ }^{6}$.

Пленума Верховного Суда РФ в постановлении от 17 января 1997 г. «О практике применения судами законодательства об ответственности за бандитизм» указал: «Оружие становится таковым при совершении

${ }^{5}$ См.: Тихонов Е.Н. Криминалистическое понятие огнестрельного оружия Избранные труды / Е.Н. Тихонов; сост. д.ю.н., профессор В.К. Гавло. - Барнаул: Изд-во Алт. ун-та, 2008. - C. 55 .

${ }^{6}$ См.: Заключение эксперта №365/17-1, 393/28-1 от 14 мая 2009 г. Архив Приморской лаборатории судебной экспертизы МЮ РФ за 2009 год. преступления только при условии его исправности, годности к использованию по назначению или возможности приведения в пригодное для использования состояние»7. По мнению А.И. Бойцова, которое заслуживает внимания, возможна и такая ситуация, когда преступник не применяет оружие по прямому назначению, то есть не производит выстрела, а наносит, например, удар рукояткой пистолета по голове, то следует расценивать как предмет, используемый в качестве оружия ${ }^{8}$.

Применение предмета, не являющегося огнестрельным оружием, но используемого в качестве оружия, рассматривается в качестве квалифицирующего признака, так как с его помощью непосредственно оказывается влияние на психическое и физическое состояние потерпевшего и тем самым достигается преступный результат, например, при грабеже, изнасиловании и др. Кроме того, с учетом обстоятельств дела возникает вопрос об ответственности по статьям 222-226 УК РФ.

Законодатель в статьях использует термин «предметы», который, исходя из буквального текста закона, становится оружием: «а равно с применением оружия или предметов, используемых в качестве оружия». На наш взгляд, данное положение не согласуется с Ф3 «Об оружие», в котором под оружием понимаются устройства и предметы, конструктивно предназначенные для поражения живой или иной цели, подачи сигналов. Исходя из этого не всякий предмет является оружием, но будет орудием совершения преступления, так как используется при совершении действий, непосредственно приводящих к общественно опасным последствиям ${ }^{9}$.

Оценка отнесения предмета к огнестрельному оружию на практике носит субъективный характер, при экспертизе аналогичных предметов эксперты приходят к противоположным выводам. В ряде случаев эксперты без проведения соответствующих исследований дают вероятный вывод: вероятнее всего пистолет пригоден к стрельбе. Экспериментальные выстрелы не проводились из-за отсутствия патронов у эксперта. Вероятный вывод не может быть положен в основу обвинительного

\footnotetext{
${ }^{7}$ См.: Постановление Пленума Верховного Суда РФ от 17 января 1997 г. «О практике применения судами законодательства об ответственности за бандитизм». Российская газета, 1997, 30 янв.

${ }^{8}$ См.: Бойцов А.И. Хищение с применением насилия, не опасного для жизни или здоровья, либо с применением оружия или предметов, используемых в качестве оружия // Полный курс уголовного права: В 5 т. / Под ред докт. юрид. наук, проф., заслуженного деятеля науки РФ А.И. Коробеева. Т. ІІІ: Преступления в сфере экономики. - СПб.: Издательство Р. Асламов «Юридический центр Пресс», 2008. - С. 254.

${ }^{9}$ См.: Хвалин В. О понятии орудия преступления // Уголовное право, №2. 2000. - С. 94.
} 
приговора, так как содержит в себе сомнения, что пистолет является оружием, следовательно, руководствуясь общими принципами, отсутствует и ответственность.

Анализ экспертной практики свидетельствует, что отдельные эксперты вопреки нормам федерального закона «Об оружии» не признают огнестрельным оружием пистолеты «Оса», «Стражник», «Лидер», а также патроны к ним в качестве боеприпасов. Это свидетельствует о том, что эксперты не знают закон и постановление Пленума Верховного Суда РФ «О судебной экспертизе» от 21 декабря 2010 года. Из этого следует и «калужская», и «казанская» экспертная практика.

Другими предметами, используемыми в качестве оружия, но не являющимся таковым, являются различные виды клинкового и ударно-раздробляющего холодного оружия, а также предметы хозяйственно-бытового назначения конструктивно сходные с ним: ножи, кастеты, сюрикены, нунчаку и др.

Например, если нож, клинок которого изготовлен из непрочного металла, в ходе экспертного исследования при нанесении ударов в сторону большого пальца и в сторону мизинца деформируется, то это не позволяет признать его оружием. Отдельные предметы туристического назначения по своим характеристикам не уступают холодному оружию, кроме одного - толщине обуха, что не позволяет экспертам, руководствуясь соответствующими методиками, относить их к холодному оружию. Однако любой из них можно использовать для разрезания ткани шеи и тогда, безусловно, он является предметом, используемым в качестве оружия. Следственная и экспертная практика свидетельствует, что, именно, эти предметы часто используются в качестве оружия совершения преступления.

Так, на экспертизу следователь представил самодельный нож, которым был причинён тяжкий вред здоровью. В соответствии с результатом сравнительного исследования эксперт установил, что данный нож изготовлен самодельным способом по типу охотничьих ножей общего назначения, но по техническим характеристикам не соответствует нормативно установленным требованиям для нескладных охотничьих ножей общего назначения и не является холодным оружием ${ }^{10}$.

По другому делу на экспертизу были предоставлены нунчаку. В заключении эксперт указал, что нунчаку применяются для нанесения ударов плашмя, ударов торцевой частью, удушающих приемов. Минимальная сила удара нунчаку, необходимая для повреждения костей черепа, составляет 1300-2000 $\mathrm{H}^{11}$. Однако, учи-

\footnotetext{
${ }^{10}$ См.: Заключение эксперта от 23.022011 г. Архив ЭКО ФРОВД УВД ПК МВД РФ за 20011 год.

${ }^{11}$ См.: Завьялов В.Л. Определение возможности нанесения
}

тывая повреждение конструкции и деформацию одного из стержней (на момент исследования), представленные нунчаку не соответствуют требованиям холодного оружия данного типа. По другому делу нунчаку были изготовлены из плотно свернутых слоев картона и покрашены темной красной, что придавало им боевой вид. В ходе экспертизы было установлено, что при нанесении ударов, картон мялся и не оставлял следов, достаточных для поражения цели.

Применительно к холодному оружию необходимость назначения криминалистической экспертизы по установлению относится ли предмет к холодному оружию не имеет смысла, так как в нормах уголовного права установлено тождество: оружие или предмет, используемый в качестве оружия. Важно установить, что именно данный нож использовался в качестве оружия.

Следователи все ножи направляют на экспертизу холодного оружия. На вопрос, зачем необходима им эта экспертиза, они отвечают для установления истины по делу, для установления обстоятельств, по делу, для суда. Возникает вопрос, о необходимости и доказательственном значении выводом проводимых криминалистических экспертиз холодного оружия. Не зависимо от того является или нет предмет холодным оружием, который использовался при совершении преступления, он законодателем признается оружием, а поэтому выводы эксперта по этому вопросу не имеют значения. Огромное количество проведённых криминалистических исследований, это пустая трата времени. Данная практика была бы целесообразной при наличии в уголовном кодексе РФ уголовной ответственности аналогичной ч. 2 ст. 218 УК РСФСР. Однако законодатель её исключил, а это означает, что все исследования холодного оружия потеряли уголовно-правовое значение.

Необходимо обратить внимание ещё на один существенный момент. Установление юридических фактов поставлено в прямую зависимость от результатов криминалистического исследования по решению экспертом задачи, связанной с определением групповой принадлежности неизвестного предмета ${ }^{12}$. Если при исследовании объектов, предоставленных на экспертизу холодного оружия это не имеет значение, то предположительный вывод эксперта, что предмет не является огнестрельным оружием, не пригоден к стрельбе, влечет серьёзные последствия. Полагаем, такая практика должна быть исключена.

телесных повреждений ударно-раздробляющим холодным оружием типа нунчаку // Экспертная практика. Вып. 23. - М.: ВНИИ МВД СССР, 1984.

${ }^{12}$ См.: Шашкин С.Б. Идентификация и доказывание // Российский следователь. №7. 2002. -С.4. 
В ст. 30 УК РФ, в ч. 5 ст. 33 УК РФ законодатель использует термин «орудия» совершения преступления. Под орудием физического насилия в науке уголовного права понимается естественное явление или предмет материального мира, которые используются виновным для непосредственного оказания ими энергетического воздействия на органы и ткани человека ${ }^{13}$.

Орудия физического насилия Р.Д. Шарапов делит на две группы: орудия - естественные явления; орудия - предметы ${ }^{14}$. Группа орудий - предметов многочисленная, но чаще всего при совершении преступлений фигурируют всевозможные виды оружия. Следовательно, в большинстве случаев орудия - это различные виды оружия, тем самым отсутствует четкое различные между орудиями и оружием.

Об отграничении орудий от других средств совершения преступления пишет и В. Хвалин. Он выделил у орудий следующие признаки: а) использование предмета или вещества, обладающего свойствами деструктивного или конструктивного воздействия на другие материальные объекты, с которыми преступник вступает во взаимодействие на каком-либо этапе или на всем протяжении своего уголовно наказуемого поведения (деятельности); осуществление процесса реального воздействия (либо попытки воздействовать при неудачном покушении) на иную материальную систему или ее элемент (физическое лицо, имущество, денежные средства, памятник, водный источник и т.д.) в целях уничтожения, полного либо частичного видоизменения, преобразования её качественно-количественных и иных характеристик; в) это воздействие привело (либо могло привести, но по каким-то причинам не привело) к ожидаемому эффекту со знаком плюс или минус ${ }^{15}$.

В качестве примера орудия совершения преступления автор приводит промах киллера, стрелявшего в свою жертву из огнестрельного оружия. Здесь также орудие совершения преступления - это оружие. Выше приведенные положения ученых не содержат четких разграничений оружия и орудий. На практике к орудиям преступления относят все виды огнестрельного и холодного оружия. Действительно, оружие является орудием совершения преступления, так как оно предназначено для поражения цели (ст. 1 Ф3 «Об оружии»), но не каждое орудие является оружием, так как он не имеет данного целевого назначения. Важно, как правильно отметил В. Хвалин, что этот предмет или вещество используется преступником для противоправного воздействия на предмет (предметы) своей активности, обусловившей наступление общественно опасных последствий либо создавшей реальную угрозу их наступления ${ }^{16}$.

\section{Библиография:}

1. Федеральный закон «Об оружии». http://www.zakonrf/zoboruzhii/1/. Запрос 16.12.2011.

2. Шарапов Р.Д. Преступное насилие. - М.: Изд-во Юрлитинформ, 2009. - С. 388.

3. Тихонов Е.Н. Криминалистическое понятие огнестрельного оружия Избранные труды / Е.Н. Тихонов; сост. д.ю.н., профессор В.К. Гавло. - Барнаул: Изд-во Алт. ун-та, 2008. - С. 55.

4. Заключение эксперта №365/17-1, 393/28-1 от 14 мая 2009 г. Архив Приморской лаборатории судебной экспертизы МЮ РФ за 2009 год.

5. Постановление Пленума Верховного Суда РФ от 17 января 1997 г. «О практике применения судами законодательства об ответственности за бандитизм». Российская газета, 1997, 30 янв.

6. Бойцов А.И. Хищение с применением насилия, не опасного для жизни или здоровья, либо с применением оружия или предметов, используемых в качестве оружия // Полный курс уголовного права: В 5 т. / Под ред докт. юрид. наук, проф., заслуженного деятеля науки РФ А.И. Коробеева. Т. ІІІ: Преступления в сфере экономики. - СПб.: Издательство Р. Асламов «Юридический центр Пресс», 2008. - С. 254.

7. Хвалин В. О понятии орудия преступления // Уголовное право, №2. 2000. - С. 94.

8. Заключение эксперта от 23.022011 г. Архив ЭКО ФРОВД УВД ПК МВД РФ за 20011 год.

\footnotetext{
${ }^{13}$ См.: Шарапов р.Д. Физическое насилие в уголовном праве.

- СПб.: Изд-во Юридический центр Пресс, 2001. - С. 153.

${ }^{14}$ См.: Шарапов Р.Д. Преступное насилие. - М., 2009. - С. $379-$

391; Он же: Физическое насилие в уголовном праве. - СПб.:

Изд-во Юридический центр Пресс», 2001. - С. 153;
}

\footnotetext{
${ }^{15}$ См.: Хвалин В. О понятии орудия преступления // Уголовное право, №2. 2000. - С. 95-96.

${ }^{16}$ См.: Там же. - С. 94.
} 
9. Завьялов В.Л. Определение возможнолсти нанесения телесных повреждений ударно-раздробляющим холодным оружием типа нунлчаку // Экспертная практика. Вып. 23. - М.: ВНИИ МВД СССР, 1984.

10. Шашкин С.Б. Идентификация и доказывание // Российский следователь. №7. 2002. -С.4.

11. Шарапов р.Д. Физическое насилие в уголовном праве. - СПб.: Изд-во Юридический центр Пресс, 2001. - С. 153.

\section{References (transliteration):}

1. Sharapov R.D. Prestupnoe nasilie. - M.: Izd-vo Yurlitinform, 2009. - S. 388.

2. Tikhonov E.N. Kriminalisticheskoe ponyatie ognestrel'nogo oruzhiya Izbrannye trudy / E.N. Tikhonov; sost. d.yu.n., professor V.K. Gavlo. - Barnaul: Izd-vo Alt. un-ta, 2008. - S. 55.

3. Boytsov A.I. Khishchenie s primeneniem nasiliya, ne opasnogo dlya zhizni ili zdorov'ya, libo s primeneniem oruzhiya ili predmetov, ispol'zuemykh v kachestve oruzhiya // Polnyy kurs ugolovnogo prava: V 5 t. / Pod red dokt. yurid. nauk, prof., zasluzhennogo deyatelya nauki RF A.I. Korobeeva. T. III: Prestupleniya v sfere ekonomiki. - SPb.: Izdatel'stvo R. Aslamov «Yuridicheskiy tsentr Press», 2008. - S. 254.

4. Khvalin V. O ponyatii orudiya prestupleniya // Ugolovnoe pravo, №2. 2000. - S. 94.

5. Zav'yalov V.L. Opredelenie vozmozhno $\neg$ sti naneseniya telesnykh povrezhdeniy udarno-razdroblyayushchim kholodnym oruzhiem tipa nun $\neg$ chaku // Ekspertnaya praktika. Vyp. 23. - M.: VNII MVD SSSR, 1984.

6. Shashkin S.B. Identifikatsiya i dokazyvanie // Rossiyskiy sledovatel'. №7. 2002. -S.4.

7. Sharapov r.D. Fizicheskoe nasilie v ugolovnom prave. - SPb.: Izd-vo Yuridicheskiy tsentr Press, 2001. - S. 153. 